\title{
LO REGIONAL COMO CATEGORÍA DE ANÁLISIS EN LA CONSTRUCCIÓN DE IDENTIDADES LOCALES: CHACO COMO CASO DE ESTUDIO (1850-1950)
}

\author{
Lic. en Historia María A. Zurlo \\ UNNE - IIGHI CONICET \\ e-mail: mariazurlo@gmail
}

\section{RESUMEN}

Los estudios regionales presentan, a la luz de los debates historiográficos actuales, diversos niveles de complejidad. Alguno de esos niveles nos permitirá asociar al estudio de las condiciones de construcción de identidades locales, el examen de factores como la pertenencia a un lugar, el enraizamiento, la asociación de determinados acontecimientos a un espacio físico, entre otros. Considerando que estos factores representan una 'variable territorialista' que toma como eje el concepto de identidad y sus formas de percepción, intentaremos aplicarla como categoría de análisis para revisar la consideración de lo territorial en los debates chaqueños acerca de la identidad provincial, entre 1850 y 1950.

\section{PALABRAS CLAVES:}

Historia Regional; Historia Local; Identidad; Memoria; Patrimonio Cultural; Historiografía.

\section{ABSTRACT}

Regional studies present different levels of complexity. Some of these levels will allow us to associate the study of the conditions of construction of local identities, examining factors such as belonging to a place, rooting, the association of certain events to a physical space, among others. Considering that these factors represent a 'variable territorialism' which takes as its axis the concept of identity and forms of perception, try to apply it as a category of analysis to review the consideration of the territorial debates about identity Chaco province, between 1850 and 1950.

\section{KEYWORDS:}

Regional History, Local History, Identity, Memory, Cultural Heritage; Historiography. 


\section{Lo Regional como Categoría de Análisis en la Construcción de Identidades Locales.}

Las últimas actualizaciones en torno a la conceptualización de lo local y lo regional nos muestran que la operatividad (Bandieri, S.: 2001) de tales conceptos ha trascendido los tradicionales límites y encuadres geográficos estrictos. Reformulaciones teóricas y metodológicas han hecho posible pensar que lo local/ regional no debería encasillarse en el estudio en aspectos geográficos o sólo en el examen de posibles vinculaciones económicas intrarregionales.

No es posible negar que los estudios locales/regionales tienen un fuerte vínculo con el espacio, pero además podemos considerar la naturaleza de este vínculo. (Fernández, S.: 2007). Efectivamente, los estudios locales/regionales presentan diversos niveles de complejidad. Alguno de esos niveles nos permitirá asociar al estudio de las condiciones de construcción de identidades locales el examen de factores tales como la pertenencia a un lugar, el enraizamiento, la asociación de determinados acontecimientos a un espacio físico y la asignación de significados a esos espacios. Considerando que estos factores representan una 'variable territorialista' (Fernández, S.: 2007), que toma como eje el concepto de identidad y sus formas de percepción, creemos posible su utilización como categoría de análisis para reflexionar acerca de la construcción de una definición de lo local/regional a partir de la reconstrucción de los procesos de conformación de identidades sociales.

Por otra parte, cuestiones como la memoria y la identidad han irrumpido en el panorama actual de las ciencias sociales y exigen estudios más detallados de las posibles relaciones entre estos temas y lo local/regional.

La identidad se define con parámetros que remiten a una continuidad en el tiempo y a un anclaje a determinado espacio físico; un espacio que conforma lo local, lo propio, lo que da sentido a lo próximo (Fernández, S.: 2007).

Cuando en un sitio ocurren eventos importantes para un grupo o una comunidad, lo que antes era solamente un espacio físico o geográfico puede transformarse en 'un lugar' (Jelin, E; Langland, V.: 2002) con significados particulares, cargados de sentimientos y sentidos particulares para quienes los vivieron y sus descendientes, para una colectividad. Estos lugares definidos por las autoras están inscriptos en un contexto histórico-temporal y los significados que se les atribuyen no son fijos, pueden ir variando a través de diferentes encuadres socio-políticos. Porque la identidad no es algo asegurado, invariable, sino que se ve modificada por los procesos de identificación históricamente construidos que le dan 
sentido y cohesión a un grupo social permitiéndole asumirse como unidad en diversos niveles de identificación (Fernández, S.: 2007). De esos niveles posibles, uno es el plano regional; es decir, que el concepto de identidad se halla ligado a la configuración social del espacio; lo local y lo regional (que Sandra Fernández define como categorías socialmente espacializadas) pueden comprenderse no sólo como espacio físico, geográfico, sino que se trata, mas bien, de aplicar una 'mirada local' que permita analizar problemas e interrogantes relativas a las formas de construcción y percepción identitarias generadas por los actores en sus dinámica social, "así tanto lo local como lo regional pasan a ser categorías flexibles que pueden hacer referencia a múltiples dimensiones espaciales (puede ser un barrio, una ciudad, una comunidad, una comarca, etc.)... la tarea fundamental es reflexionar sobre determinados ejes problemáticos en estos espacios pensados como entidades construidas socialmente" (Fernández, S.: 2007: 39). En palabras de Jelin: "el núcleo de cualquier identidad individual o grupal está ligado a un sentido de permanencia (de ser uno mismo, de mismidad) a lo largo del tiempo y del espacio."(Jelin, E.: 2002: 24)

El interés en la descripción y conocimiento del Chaco podría remontarse ya a los religiosos misioneros, a los conquistadores y viajeros que, en diversas etapas de su historia, se internaron en la región y detallaron aspectos etnográficos, vivencias y testimonios conformando una imagen regional del espacio chaqueño y una crónica de su ocupación y transformación. Estos testimonios, descripciones y memorias contribuyeron a sustentar determinadas representaciones del Chaco, imágenes que serían actualizadas a la luz de los intentos de ocupación del espacio a fines del siglo XIX principalmente a través del discurso de los agentes de las diversas instituciones del gobierno nacional vinculados, de una u otra forma a las políticas de expansión y ocupación territorial (Leoni de Rosciani, Ma. S.: 2008). Funcionarios, militares y aficionados, artículos de revistas, informes y boletines describían aspectos geográficos y de la biología chaqueña y las observaciones realizadas durante las expediciones y viajes. En general estos trabajos presentarán al Chaco como un "desierto verde" un espacio sin historia, cuya existencia se inicia a partir del proceso de exploración y ocupación. Al ser un área "vacía", le corresponde a la geografía volverla objeto de conocimiento y ocupar así un lugar privilegiado en la formación de una conciencia territorial nacional. (Leoni de Rosciani, Ma.S.: 2008) Es común entonces que el Chaco sea conceptualizado, en este momento, con alusiones a su geografía; así, como mencionamos 
anteriormente, Chaco aparece sinonimado con expresiones como desierto verde, espacio vacío, territorio inhóspito, entre otros.

Tras el fin del periodo de conquista y colonización, una vez consolidado el proceso de incorporación al sistema nacional, surgirá la necesidad de elaborar una nueva imagen del Chaco, que superara aquellos antiguos relatos y mostrara los avances obtenidos por sus habitantes (Leoni, Ma. S.: 2006)

Nuevamente desde el ámbito nacional, publicaciones, exposiciones, libros y folletos combatirán la imagen de desierto con que se representaba a los territorios, divulgarán variados aspectos de la vida territoriana, buscando difundir información pero también llamar la atención del gobierno y la opinión pública hacia la problemática de estas regiones. Esta preocupación existió también en el ámbito local, las representaciones que existían sobre el Chaco contrastaban con la realidad que ofrecía Resistencia a principios del siglo XX e interesaba a los chaqueños cambiar una visión que se percibía errónea (Leoni de Rosciani, Ma. S.: 2008).

Con todo, el ámbito gubernamental y la opinión pública nacional no desconocían el progreso económico y demográfico del Chaco, considerado ahora como un verdadero 'crisol de razas', un territorio pujante. No serán ya las características geográficas las que definirán al Chaco sino el sostenido avance demográfico, el progreso material y la modernidad que caracterizaban la vida chaqueña en esta etapa. En Resistencia, los pensadores e intelectuales locales intentarán darle al territorio un perfil cultural propio, que incluyera a los mas diversos sistemas culturales que convivían en él y cuya coexistencia generaba esa idea de inexistencia de identidad y de lazos de pertenencia, de ausencia, en definitiva, de un marco cultural e identitario propio.

Revisar el tema de la identidad del Chaco, entonces, nos remite a la pregunta inicial sobre qué noción del Chaco subyace en cada etapa de su trayectoria histórica, en cada una de las imágenes que sobre su pasado se erigieron, en cada uno de los actores e instituciones que abordaron el tema y en qué medidas estas cuestiones permiten un análisis desde lo local/regional.

Términos específicamente relacionados con el lugar geográfico, como región, territorio, espacio vacío, desierto verde, tierra de indios, así como otras denominaciones vinculadas con su población, sociedad o cultura, semejantes a 'crisol de razas', 'moderna Fenicia', 'Chaco gringo', o finalmente, que corresponden a una realidad económica, tal es el caso de 
Revista Geográfica Digital. IGUNNE. Facultad de Humanidades. UNNE. Año 9. № 17. Enero - Junio 2012. ISSN 1668-5180 Resistencia, Chaco

expresiones como 'hacer Chaco' o 'pujanza chaqueña' por ejemplo hacen referencia al Chaco, en diversas etapas de su historia y a diferentes perspectivas con que se abordó su conocimiento.

La determinación de un marco regional para el Chaco obligaría a sus intelectuales a pensar el tema, a abordarlo desde diversas perspectivas, en los intentos por construir una conceptualización de Chaco. Se necesitaba una definición que diera encuadre al Chaco en un espacio físico, que lo insertara regionalmente en un ámbito del que se reconociera parte integrante. Guido Miranda ${ }^{1}$, así, define la región chaqueña desde una óptica económica pero concluirá por incluirla en la región Nordeste y afirmará que toda ésta posee una identidad propia con base en la ocupación humana, homogeneizada por la cultura guaraní (Leoni de Rosciani, Ma. S.: 2008)

Por su parte, Ramón Tissera ${ }^{2}$, quien se opone a la concepción de región Nordeste y a la inclusión de la provincia en ella, propone el concepto de 'Gran Chaco', con bases geopolíticas e históricas que permitirían finalmente plantear la definición de una identidad para el Chaco. El autor consideraba que la inserción del Chaco en otros esquemas regionales generaría la pérdida de aquellas características propias de la personalidad chaqueña (Leoni de Rosciani, Ma. S.: 2008). ${ }^{3}$

Objeto de análisis, reflexión y debates, la noción de Chaco, su conceptualización e identidad regional han sido cuestiones constantes en la historiografía chaqueña, aun antes de que ésta se erigiera como tal. Los intelectuales chaqueños reconocieron desde temprano la importancia de la delimitación este concepto para la reconstrucción de la trayectoria histórica del Chaco y para abordar el examen y definición de una identidad propiamente chaqueña.

Por un lado entonces, "surgiría la cuestión regional: ¿a qué región pertenecía el Chaco? La determinación de ella, a su vez, permitiría caracterizar lo típicamente chaqueño. El problema de la inserción regional del Chaco respondió a los cambios producidos dentro de la política nacional con respecto a la determinación de regiones para una mejor planificación. Las diversas posturas con respecto a la definición del término 'región' conducirían también a delinear límites diversos." (Leoni, Ma. S.: 2006). Asociado, entonces, a la temática de la

\footnotetext{
${ }^{1}$ Guido Miranda, historiador chaqueño, escritor de varios libros. Su obra es una visión globalizadora, integradora y dinámica del proceso histórico chaqueño. Fue periodista y redactor de varios periódicos y revistas.

${ }^{2}$ Ramón Tissera, reconocido político, periodista e investigador histórico, interessado em temas chaqueños.

${ }^{3}$ Para Tissera, el gran Chaco se caracterizó desde sus orígenes por una generalizada homogeneidad físico-biológica y una población aborigen, que impidió asentamientos perdurables de los 'blancos' hasta el siglo XIX, surgiendo así las leyendas acerca de las dificultades insuperables para habitar el territorio. Estas leyendas contribuyeron a mantener la configuración del Gran Chaco como unidad territorial, favorecido por la situación política, ya que una vez incorporado a la nación, el territorio no tuvo modificaciones político-institucionales hasta la década de 1950 cuando fuera provincializado.
} 
identidad chaqueña, está la consideración de su definición como región, definición que no carece de importancia ya que brindará el marco geográfico, político, económico, social y cultural desde el cual se plantearán las preguntas tendientes a delimitar los elementos identitarios propiamente chaqueños.

Una vez asegurada la pacificación y organización del territorio y a partir del crecimiento de Resistencia, ciudad capital, se planteó la necesidad de una base identitaria propia para el Chaco, se comienza a pensar en la existencia de sentimientos de pertenencia que dieran cohesión a una población chaqueña de variadísimos orígenes, que construyeran lazos de pertenencia con un espacio delimitado geográficamente en el que los chaqueños se identificaran como tales. Se creía que el progreso económico debía ser paralelo al desarrollo de dichos sentimientos de pertenencia. Se darían así los primeros pasos en la búsqueda de los orígenes, los elementos culturales característicos, la identidad chaqueña. Personajes de sobresaliente trayectoria en el ambiente sociocultural y político se mostrarían interesados por indagar y reconstruir el surgimiento y transformación chaqueños.

Teóricamente, "en el proceso histórico de construcción de territorialidades 'sentidas', cuenta especialmente la experiencia humana. Se trata de ver al 'lugar' como manifestación de la experiencia y del sentido, conectado con unas prácticas sociales... historias vitales... situados en un espacio con dimensiones geográficas" (Del Pino, P.; Jelin, E.: 2003: 3)

A lo largo de nuestro período de estudio se evidencia, a través del discurso político y periodístico, la intención de recuperar este sentido de la propia construcción de comunidad, la revalorización de la idea de un anclaje territorial ligado a experiencias compartidas, formando la base de un escenario de vida transformación; estableciéndose un pasaje entre un pasado considerado prolífico y un futuro esperado con expectativas, a través de un presente, que hace de puente $y$, en cierto modo, impone a los chaqueños mantener vigentes valores e imágenes del pasado.

Por su parte, Langland (Jelin, E.; Langland, V.: 2002) asegura que la territorialidad puede en última instancia, no ser un lugar físico especifico, sino estar representado por una trayectoria, un recorrido, una manera de revivir el pasado, plasmado en una práctica territorializada.

En diversas oportunidades, como mencionáramos, se señaló la necesidad de generar ideales de pertenencia y sentido de identificación de una población, de diverso origen y culturas, heterogénea y dinámica, como argentinos y chaqueños y se construyeron, para tal 
fin, múltiples representaciones del pasado, que buscaban legitimar determinados grupos o actores que habrían sentado las bases de esa sociedad chaqueña, caracterizada por su diversidad. Cada una de estas representaciones proponía un origen para Chaco, y lo vinculaba con un determinado grupo de actores sociales relacionados con el uso, permanencia o asentamiento definitivo en un determinado espacio físico, en relación con un modelo proyectado de provincia, en un marco de contextualización propuesto implícitamente para tomar el lugar que le correspondía como provincia en el ámbito nacional. Así, los principales debates intelectuales chaqueños buscarían dirimir la cuestión de las diversas interpretaciones que se proponían sobre el pasado chaqueño, "en un juego de fuerzas que pareciera haber terminado por imponer hasta hoy la visión de un Chaco gringo" (Leoni, Ma. S.: 2004: 11) sin que ello significara la eliminación de los relatos alternativos que contribuirían, a futuro, con nuevos contenidos y nuevos actores al proceso de construcción de una identidad chaqueña. Estos relatos delinean perfectamente diversas representaciones del pasado local. En primer lugar, la perspectiva que defiende un pasado vinculado a la historia de Corrientes. Se buscó hacer prevalecer el esfuerzo de los correntinos que habían contribuido en esta gesta, ya fuera a través de las acciones emprendidas por sus gobernantes o por el trabajo de sus obrajeros, atribuyéndoles un papel destacado como edificadores del Chaco. Representantes de esta línea habían sido anteriormente los historiadores correntinos Manuel Mantilla y Hernán Gómez, que abordaron la temática como vinculación a la historia de Corrientes. También Federico Palma había defendido esta postura en sus debates con Juan R. Lestani, en las páginas del diario El Territorio, en la década del 30 (Leoni, Ma. S.: 2004). Esta perspectiva correntinista se habría fijado a lo largo del tiempo como una de las posibles representaciones del pasado, conviviendo con otras, sin ser aceptada unánimemente; implícitamente significaba la incorporación del Chaco a un espacio regional supeditado a la órbita correntina; ni sin cierta crítica a la actuación política correntina que habría interferido en cuestiones puramente locales chaqueñas.

Otra orientación, que se plantearía a partir de la década de 1940, tenía como difusora a la Iglesia Católica chaqueña y proponía buscar las raíces provinciales en un pasado más lejano, hispánico y católico. Entre los cultores de esta corriente se destacan Ricardo Zalazar y Monseñor Alumni ${ }^{4}$. Este último sostenía se debían recuperar las raíces católicas de la

\footnotetext{
${ }^{4}$ Ricardo Zalazar incursionó en el estudio de la historia de la Iglesia y, publicaría, Historia de la Iglesia en el Chaco. Reseña de sus hechos, en 1976. Monseñor Alumni, radicado en el Chaco entre 1936 y 1956, realizó trabajos arqueológicos y estudio la obra de los jesuitas en el Chaco. Ambos tuvieron, como ya mencionáramos, una destacada participación en la cultura chaqueña a través de las instituciones católicas de gran peso en la sociedad chaqueña.
} 
Revista Geográfica Digital. IGUNNE. Facultad de Humanidades. UNNE. Año 9. № 17. Enero - Junio 2012. ISSN 1668-5180 Resistencia, Chaco

cultura chaqueña y revalorizar una tradición anterior a la etapa territoriana, analizando el papel del Chaco en el contexto general de la conquista. (Leoni, Ma. S.: 2004) Los intentos por establecer una identificación entre el Chaco actual y el pasado hispánico y católico se enmarcaron en el contexto del hispanismo católico impulsado por Perón, en un esfuerzo por formar en la sociedad argentina una nueva conciencia nacional. Se buscó así integrar a los chaqueños dentro de dicha conciencia, haciendo secundario el papel de la inmigración en la construcción del Chaco.

Finalmente, fue muy exitosa la perspectiva que tomaba como hito inicial del proceso histórico, la colonización de Resistencia, producto de la inmigración. Se buscaba demostrar la independencia del desarrollo chaqueño, respecto de Corrientes o de las etapas históricas anteriores. Se hace protagonistas de aquel desarrollo a la tenacidad y esfuerzo del inmigrante. Se instala entre los chaqueños a partir de la década de 1920, cuando se intenta imponer en la comunidad la conmemoración de la fundación de la ciudad de Resistencia, a la llegada en 1878 de los primeros inmigrantes italianos.

Entre las figuras que adhirieron a esta línea interpretativa podemos citar a Juan R. Lestani ${ }^{5}$, Seferino Geraldi ${ }^{6}$ y Carlos López Piacentini ${ }^{7}$. Resultan particularmente interesante los debates entre estos personajes, en el seno de la revista Región, el cuestionamiento del verdadero aporte de los inmigrantes italianos: algunos, por ejemplo Guido Miranda, afirmaban que "la población, el origen del Chaco moderno es correntino..." y otros, por ejemplo, Tissera decían "acá el que tuvo el valor de llegar era el criollo... y lo que hicieron los inmigrantes fue venir después y poblar, quedarse..."

Más allá de los debates, Resistencia contaba en ese entonces, como todavía cuenta hoy, con múltiples lugares de memoria $^{9}$ que reforzaban la centralidad de la inmigración italiana en la construcción del Chaco (Leoni, Ma. S.: 2002). Esta imagen sobre los inicios del Chaco se instalaría con fuerza, perdurando a lo largo del tiempo y manteniendo su vigencia, incluso

\footnotetext{
${ }^{5}$ Juan R. Lestani, descendiente de las primeras familias italianas que llegaron para poblar Resistencia en 1878. Incorporado al socialismo, fue el primer intendente nativo de Resistencia. Colaboró y dirigió La Verdad, periódico socialista; también dirigió Región y publico El territorio Nacional del Chaco. (Oro y miseria) en 1935, señalando la problemática derivada del progreso económico y defendiendo la provincialización.

${ }^{6}$ Seferino Geraldi tuvo una destacada participación en diversas instituciones culturales, a la vez que desarrollo una importante actividad periodística. Descendiente de los inmigrantes friulanos, publico, entre otros, Lo que me contaron mis abuelos en 1965.

${ }^{7}$ Carlos López Piacentini se interesó por el estudio y difusión de temáticas vinculadas a la antropología, historia, folklore, ciencias naturales en el Chaco. Busco despertar la conciencia histórica de los chaqueños y fortalecer el sentido de pertenencia, a través de la publicación de múltiples trabajos, conferencias, material para las escuelas primarias e Historia de la Provincia del Chaco en 1969-70 y 1979 una nueva edición ampliada a 5 volúmenes.

${ }^{8}$ Entrevista a Marcos Altamirano. Resistencia, noviembre de 2008.

${ }^{9}$ Para una conceptualización de "lugares de memoria", Nora, Pierre. "La aventura de Les liux de memoire". En: Josefina Cuesta Bustillo (Comp.) Memoria e Historia. Marcial Pons, Madrid, 1999. También, Jelin, E. (Comp.) Los trabajos de la memoria. Siglo XXI de España Editores, Madrid, 2002.
} 
hasta la actualidad; de tal manera que 'oficialmente' los colonos aparecen como los verdaderos forjadores del Chaco (Leoni, Ma. S.: 2002), ejemplo a imitar por sus grandes méritos. En 1951, se cumplían sesenta años de la fundación de la Asociación Italiana. La institución editaría una obra titulada Libro de Oro 60 Aniversario de la Asociación Italiana de Socorros Mutuos de Resistencia ${ }^{10}$. A lo largo de sus páginas recorre la trayectoria de la inmigración italiana y su aporte al desarrollo chaqueño, resaltada a través de artículos escritos por reconocidas figuras de la cultura e intelectualidad resistenciana de la época, como por ejemplo, Monseñor José Alumni, Adolfo Cristaldo, Carlos Primo López Piacentini, entre otros. La llegada de los contingentes italianos al Chaco, su instalación en el espacio geográfico que actualmente corresponde a Resistencia y la construcción y el progreso de un escenario regional basado en las características culturales impresas por la inmigración continúa vigente como representación del pasado chaqueño: “... ¿Cuál es ese territorio que ya estaba conquistado cuando desembarcaron las familias italianas en el puerto de San Fernando?... No debe ser... nuestro Chaco, ¿porque dónde estaban esos núcleos de población?... fuera de los pocos obrajeros que en forma esporádica y fuertemente armados, con la protección de las tropas correntinas, venían cortar maderas en los montes del litoral, no existía en toda la extensión de Chaco ni siquiera una minúscula localidad... aceptablemente civilizada." ${ }^{11}$ En este contexto, el surgimiento de Resistencia tuvo especial relevancia. La efectivización de la ocupación del espacio en el territorio Nacional del Chaco, así como el establecimiento de su sistema urbano surgió con el poblamiento definitivo de Resistencia, en un espacio considerado un 'desierto verde'. Como ya vimos, de los textos de la publicaron se desprende la convicción de que el doblamiento definitivo de este desierto verde se inició en 1872 y se consolidó con las oleadas inmigrantes italianas posteriores, que generarían una colectividad de gran peso a nivel local.

Las expresiones terruño, patria chica, que aparecen en artículos, ensayos y entrevistas periodísticas, nos remiten a pensar en un concepto regional del Chaco, implícito pero existente, en el que además de la cuestión de los orígenes, sobre la que existirían aún debates; se plantea el interés y la necesidad del Chaco de ocupar un lugar en el contexto nacional.

Ramón Tissera, que defendía el reconocimiento del papel del aborigen como actor del pasado chaqueño, proponía buscar las raíces de la identidad chaqueña en los primitivos

\footnotetext{
${ }^{10}$ Bueno, F., Ed. Libro de Oro. 60 Aniversario de la Asociación Italiana de Socorros Mutuos. Ed. Corrientes; Resistencia, 1952. ${ }^{11}$ LO, Pág.. 10.
} 
Revista Geográfica Digital. IGUNNE. Facultad de Humanidades. UNNE. Año 9. № 17. Enero - Junio 2012. ISSN 1668-5180 Resistencia, Chaco

pobladores, los grupos aborígenes; y criticaba, en general, las versiones que hacían nacer al Chaco en épocas mas recientes, olvidando o dislocando la etapa anterior al siglo XIX, y considerada poco valiosa, a los efectos de la fijación de la mencionada identidad (Leoni, Ma. S.: 2004). El autor explica que considera necesario incluir en el pasado chaqueño, actores más alejados en el tiempo, que hacen de la provincia un espacio con identidad propia, una región antiguamente delimitada por condiciones geográficas pero también por el accionar humano. En la valoración de esa identidad local, el autor se opone a incluir al Chaco en otras denominaciones regionales. A la mayoría de los autores, historiadores, periodistas, intelectuales y políticos chaqueños, les interesaba la existencia de una unidad que reforzara la individualidad chaqueña para presentarse en el escenario nacional, porque lo que estaría en juego seria la posición del Chaco en él, la búsqueda de un lugar en ese ámbito nacional. A partir de la década de 1940 habían comenzado ya los requerimientos para la obtención del status de provincia y durante la presidencia de Perón se presentaron sin éxito varias iniciativas en el Congreso Nacional. El proceso se aceleró sin embargo cuando la CGT renueva un petitorio en tal sentido a Eva Perón en 1949. A partir de allí, la influencia de Eva Perón en el Poder Legislativo Nacional logrará la transformación del Chaco en provincia por la ley $n^{\circ}$ 14.037. La medida se recibió en un clima de alegría y celebración, no exenta de aprehensión por parte de los partidos opositores. ${ }^{12}$

El proceso de redacción de una constitución para la nueva provincia conformaría un hito largamente cuestionado, criticado y repudiado por actores y sectores políticos y la opinión pública chaqueña. Ante el desafío de configurar un nuevo régimen constitucional y legal, se buscó aplicar los principios de la doctrina peronista y crear así una organización provincial en función del 'pueblo trabajador'. De esta manera, el nuevo estado constituyó una avanzada en la política peronista ${ }^{13}$. En tan solo cinco días fue aprobada una constitución para el Chaco que, a juicio de Maeder, "pareció más que el resultado de las iniciativas chaqueñas, un fruto elaborado en la Secretaría de Asuntos Técnicos... En cuanto al texto,

\footnotetext{
${ }^{12}$ Leoni de Rosciani, Ma. Silvia. Los comienzos del Chaco provincializado. IIGHI-Conicet, Resistencia, 1992. También, Ruffini, Marta. "Peronismo, Territorios Nacionales y ciudadanía política. Algunas reflexiones en torno a la provincialización (19401955)." En: Revista Avances del CESOR. Año 5, № 5, Centro de Estudios Sociales Regionales, Facultad de Humanidades y Artes, Universidad Nacional de Rosario, Rosario, 2005. Pp. 132-148.Disponible en: http://bibliotecavirtual.clacso.org.ar/ar/libros/argentina/cehepyc/ruffi.rtf

${ }^{13}$ Por disposición de la misma constitución provincial, la provincia pasó a denominarse Presidente Perón, se impusieron nombres alusivos a calles, leyes e instituciones, se adoptó el escudo peronista como escudo provincial. Leoni de Rosciani, Ma. Silvia. La conformación del campo cultural chaqueño... Pág. 105.

Ruffini explica este proceso en el contexto de la ideología peronista, que pretendía la preeminencia del poder político sobre el civil a través de la pasivización progresiva del ciudadano y la exclusión de la oposición. Ruffini, Marta. "Peronismo, Territorios Nacionales y ciudadanía política..."
} 
este ofrecía al menos tres errores fundamentales: el cambio de nombre de la provincia, un régimen arbitrario y clasista y... la supresión del carácter electivo del municipio de Resistencia."14 El cambio de nombre de la provincia y las características peculiares, tanto en contenido como formales de la Constitución de la nueva provincia generaron tensión entre los partidos políticos y la opinión pública opositores. El cambio de nombre de la nueva provincia, que pasaría a denominarse Provincia Presidente Perón, generó un ámbito en el que se debatieron exhaustivamente las consecuencias de tal cambio nominal para la identidad provincial y se reactualizaron y resignificaron imágenes del pasado chaqueño en vistas a justificar o rechazar tal modificación del nombre. Entre los actores que mayormente cuestionaron el desarrollo del proceso de provincialización, así como el nombre de la nueva provincia, figura Edgardo Rossi, reconocida figura política chaqueña, vinculada al partido socialista. Para Rossi, el cambio de nombre significaba negar la identidad cultural del pueblo chaqueño y alarmaba sobre las consecuencias que ello ocasionaría para la identidad regional (Rossi, E.: 1951).

Los actores sociales (Del Pino, P.; Jelin, E.: 2003) de una comunidad elaboran y transforman el sentido de identidad y pertenencia como parte de la nación. Para el caso del Chaco, Edgardo Rossi traduciría esta relación como "una función mediadora que las provincias pos-constitucionales podrán desempeñar en beneficio de la integración nacional, entre los históricos polos de la Capital Federal y las provincias pre-constitucionales ( Rossi, E.: 1997: 225).

Dado que la construcción de comunidad está sujeta a intereses locales y de poder, intereses recíprocos, entre grupos o actores, que generan sentidos comunes, de consenso o de identificación, no siempre lo local es un lugar común, homogéneo y ajeno a conflictos o cuestionamientos (del Pino, P.; Jelin, E.: 2003).

Las vías de construcción de una identidad chaqueña, abierta a la pluralidad y valorización de las peculiaridades culturales que definen la identidad chaqueña y la valorización del anclaje territorial, fueron argumentos frecuentemente utilizados entre los chaqueños que ansiaban que la nueva provincia participara en las decisiones nacionales con personalidad provincial propia. Las cualidades comunitarias que unifican, las que diferencian y las formas de articulación entre ellas aportan elementos transformadores a la dinámica social-comunitaria, permitiendo no solo revisar sentidos del pasado sino, como en este caso, proyectarlos a una

\footnotetext{
${ }^{14}$ Maeder, Ernesto. Historia del Chaco... Pág. 235.
} 
problemática del presente: delinear una identidad para la reciente provincia,con raíces en un espacio físico que le sirviera de marco geográfico e identitario, permitiéndole tomar con confianza su lugar entre las provincias argentinas.

Tras la Revolución Libertadora de 1955, el gobierno sería asumido por autoridades miliares que tomaron medidas tendientes a desmantelar el aparato estatal peronista. Para nuestra provincia significó recuperar el nombre Chaco así como una remoción de todo nombre o imagen alusiva al periodo peronista anterior ${ }^{15}$. Esto incluyó la inhabilitación de la Constitución provincial de 1951 y, finalmente, la aprobación de una nueva Constitución, ideológicamente opuesta a la de $1951 .{ }^{16}$ Los debates en torno a la nueva Constitución que debía sancionarse tras la derogación de la de 1951, ponen de relieve el enfrentamiento producido entre el socialismo y la Iglesia católica con respecto al espíritu y el contenido de la Ley. Estas perspectivas enfrentadas se trasladarían al campo historiográfico, para buscar las raíces históricas de las dos interpretaciones del pasado chaqueño que se venían perfilando en las etapas anteriores y que serían objeto de debates y reactualizaciones posteriores. La publicación, por Seferino Geraldi, de su obra "Lo que me contaron mis abuelos" en 1965 completaría un panorama con las distintas tendencias en la interpretación del pasado chaqueño, cada una con el énfasis colocado en alguno de sus momentos y en alguna particular corriente inmigratoria y poblacional. ${ }^{17}$

La creación y consolidación de la Universidad Nacional del Nordeste, por su parte, y el movimiento poblacional contribuirán a la conformación de nuevos subgrupos culturales. Reuniones de maestros, profesores de la Universidad, periodistas, escritores y artistas darían vida a agrupaciones que tendrían una fecunda participación en la vida cultural chaqueña. ${ }^{18}$

La relación entre el gobierno provincial y las instituciones no oficiales fue estrecha a lo largo de estos años. Aquel afirmaba su convencimiento de que el Estado no podía cumplir con eficiencia una labor tan amplia, por lo cual estimuló decididamente la constitución de organismos culturales de carácter privado. En general, estas instituciones serían consideradas auténticas constructoras de la cultura chaqueña. Activas, integradas por personalidades de la intelectualidad chaqueña y apoyadas por el gobierno provincial,

\footnotetext{
${ }^{15}$ Leoni de Rosciani, Ma. Silvia. La cultura en Resistencia. Inédito.

${ }^{16}$ Maeder, Ernesto. Historia del Chaco... Pág. 242. También, Beck, Hugo. Política y Elecciones en la Provincia del Chaco entre 1955 y 1989. Facultad de Humanidades, Dto. De Historia, Resistencia, 1991.

17 Ibíd.

${ }^{18}$ Leoni de Rosciani, Ma. Silvia. El movimiento intelectual en Resistencia...
} 
Revista Geográfica Digital. IGUNNE. Facultad de Humanidades. UNNE. Año 9. № 17. Enero - Junio 2012. ISSN 1668-5180 Resistencia, Chaco

realizaron una tarea prolífica que les brindó reconocimiento a escala nacional y hasta internacional. Afirma Rossi, "¿Tenemos clara conciencia de nuestra posición...acerca de qué es nuestro Chaco actual? En fin, ¿el Chaco tiene identidad? Sí; la posee y hondamente... La identidad del Chaco no nació como un acto, sino efecto de una suma de hechos, elementos y acciones." (Rossi, E.: 1997).

En conclusión, el recurso a los orígenes ${ }^{19}$ como forma de redescubrir lo propio que identifica y diferencia fue la estrategia pensada, planteada y propuesta por quienes se interesaron en develar la identidad chaqueña. Desde distintos ámbitos y con diferentes enfoques se buscó crear conciencia y vincular a la población chaqueña con una identidad provincial, desarrollando una conciencia histórica regional ligada a la historia y la memoria como elementos definitorios de la identidad, elementos que se presentarían, en este caso, a través de la educación o de las noticias y cuestiones que el Chaco debía rememorar. ${ }^{20}$

\section{BIBLIOGRAFÍA}

- Bandieri, Susana. "La Posibilidad Operativa de la Construcción Histórica Regional o Cómo Contribuir a una Historia Nacional más Complejizada." En: Fernández, S.; Dalla Corte, G. (Comps.) Lugares para la Historia. Espacio, Historia Regional e Historia local en los Estudios Contemporáneos. Universidad Nacional de Rosario, Rosario, 2001.

- Bonaudo, Marta. "Otra vez la 'fantasmática' historia regional..." En: Bandieri, S.; Blanco, G.; Blanco, M. (coords.). Las escalas de la historia comparada. Tomo 2: Empresas y empresarios. La cuestión regional. Miño y Dávila, Bs. As., 2008.

- Del Pino, Ponciano; Jelin, E. (comps.) Luchas locales, comunidades e identidades. Siglo XXI de España Editores, Madrid, 2003.

- Fernández, Sandra. "Los estudios de historia regional y local. De la base territorial a la perspectiva teórico-metodológica." En: Fernández, S. (Comp.). Más allá del territorio. La historia regional y local como problema. Discusiones, balances y proyecciones. Prohistoria, Rosario, 2007.

- Jelin, E. - Langland, V. (Comp.) Monumentos, memoriales y marcas territoriales. Siglo XXI, Madrid, 2002.

- Jelin, E. (Comp.) Las conmemoraciones: las disputas en las fechas "in-felices". Siglo XXI, Madrid, 2002.

- Leoni de Rosciani, Ma. Silvia. La conformación del campo cultural chaqueño. Una aproximación. Moglia Ediciones, Corrientes, 2008.

\footnotetext{
${ }^{19}$ Costa, Ricardo; Mozejko, Danuta. El discurso como práctica. Lugares desde donde se escribe la historia... Pág. 53.

${ }^{20}$ Costa, Ricardo; Mozejko, Danuta. El discurso como práctica. Lugares desde donde se escribe la historia... Pág. 63.
} 
- Leoni, Ma. Silvia. "El 2 de febrero: historia y memoria de la inmigración italiana en el Chaco." En: II Jornadas Nacionales Espacio, Memoria e Identidad, Univ. Nac. De Rosario, 2002.

- Leoni, Ma. Silvia. "Las Historiografías provinciales. Chaco y Corrientes. De los inicios a la profesionalización del campo histórico." En: revista Nordeste; Chaco, Serie Docencia, $2^{\mathrm{a}}$ Época, № 18, 2004. Pp. 37-55.

- Leoni, Ma. Silvia. "Ramón Tissera, entre historia y política en la provincia del Chaco" En: XXVI Encuentro de Geohistoria Regional. IIGHI-Conicet, Resistencia, 2006. Pp. 302-307.

- Maeder, Ernesto. Historia del Chaco. Plus Ultra, Bs. As, 1996.

- Rossi, Edgardo. Identidad del Chaco. Esbozo para un Ensayo. Meana \& Meana Impresores, Resistencia, 1997. Pp.225.

- Rossi, Edgardo. Reivindicación del Chaco. Parlamento Libre, Resistencia, 1953. 